University of Nebraska - Lincoln

DigitalCommons@University of Nebraska - Lincoln

Biological Systems Engineering: Papers and

Publications

Biological Systems Engineering

Fall 1991

\title{
Area Conservation Tillage Meetings-A Successful Educational \\ Program
}

Elbert C. Dickey

University of Nebraska at Lincoln, edickey1@unl.edu

Paul J. Jasa

University of Nebraska at Lincoln, pjasa1@unl.edu

David P. Shelton

University of Nebraska-Lincoln, dshelton2@unl.edu

Robert Grisso

Virginia Polytechnic Institute and State University, rgrisso@vt.edu

Keith Glewen

University of Nebraska-Lincoln, kglewen1@unl.edu

Follow this and additional works at: https://digitalcommons.unl.edu/biosysengfacpub

Part of the Biological Engineering Commons

Dickey, Elbert C.; Jasa, Paul J.; Shelton, David P.; Grisso, Robert; and Glewen, Keith, "Area Conservation Tillage Meetings-A Successful Educational Program" (1991). Biological Systems Engineering: Papers and Publications. 240.

https://digitalcommons.unl.edu/biosysengfacpub/240

This Article is brought to you for free and open access by the Biological Systems Engineering at DigitalCommons@University of Nebraska - Lincoln. It has been accepted for inclusion in Biological Systems Engineering: Papers and Publications by an authorized administrator of DigitalCommons@University of Nebraska Lincoln. 


\title{
Area Conservation Tillage Meetings-A Successful Educational Program
}

\author{
Elbert C. Dickey, ${ }^{*}$ Paul J. Jasa, David P. Shelton, Robert D. Grisso, and Keith Glewen
}

\begin{abstract}
Interest in conservation tillage began to increase in the early 1980s, and farmers wanted information on how to adopt and manage various tillage and planting systems. Area conservation tillage meetings were developed by the University of Nebraska Cooperative Extension to provide the needed information on a regional basis. Local extension agents and Soil Conservation Service personnel helped extension specialists determine program content. The multidisciplinary meetings included farmer presentations and allowed space and time for commercial exhibits. About $80 \%$ of respondents to meeting evaluations indicated they planned to change their tillage practices as a result of the information presented.
\end{abstract}

$\mathrm{S}^{\mathrm{o}}$ IL erosion, sedimentation, and subsequent impacts on water quality are major problems associated with Nebraska crop production (NNRC, 1979). Eastern Nebraska, especially the northeastern portion, has a history of severe soil erosion due in part to a predominance of steep slopes and highly erodible soils. The average annual allowable soil loss ( $T$ value) is 11.2 $\mathrm{t} / \mathrm{ha}$ for most Nebraska soils, yet some fields have annual soil erosion rates exceeding $225 \mathrm{t} / \mathrm{ha}$. Loss of topsoil is critical; erosion can result in the removal of fertilizers and pesticides, thus contributing to water quality problems and reduced crop yields.

Although farmers often are aware that erosion is a problem nationally, many do not recognize it as a problem in their own operations. Sheet and rill erosion, two of the most common forms of soil loss, may be largely invisible to farmers (Nowak, 1985). Further, while soil erosion has occurred, farmers generally have not experienced corresponding losses in productivity. In many cases, potential losses have been masked by increased inputs of fertilizer, improved hybrids, and irrigation.

Structural and nonstructural conservation practices can be used to reduce soil losses to acceptable levels. Conservation tillage is one of the most effective and least costly methods of reducing soil erosion while conserving labor, fuel, and soil moisture. Depending on residue type, a variety of tillage and planting systems can be classified as conservation tillage. These can include no-till,

E.C. Dickey, P.J. Jasa, and R.D. Grisso, L.W. Chase Hall, Univ. of Nebraska, Biological Systems Eng. Dep., Lincoln, NE 68583; D.P. Shelton, Univ. of Nebraska Northeast Res. and Ext. Center, Concord, NE 68728; and K. Glewen, Univ. of Nebraska Coop. Ext. in Saunders County, 112 East 7th, Wahoo, NE 68066. Published as Journal Series no. 90-9, CASNR, Univ. of Nebraska. Received 13 Nov. 1990. *Corresponding author.

Published in J. Agron. Educ. 20:115-119 (1991). ridge-till, and even disking and chiseling if the number of residue-altering operations is limited to maintain at least a $30 \%$ residue cover on the soil surface after planting (CTIC, 1989). Even when farmers recognize the erosion problem, they may not realize that residue management practices can reduce soil losses. Further, they may not have the appropriate information about what constitutes conservation tillage.

Although researchers, Cooperative Extension (CE) personnel, conservation workers, and producers have documented the advantages of conservation tillage systems, adoption in some row crop producing areas has been less than anticipated. Ideally, the frequency of application of conservation practices should increase as inherent erosion potential increases. However, this does not appear to be the case. According to the 1982 Natural Resources Inventory, for the nation as a whole, the percentage of land area treated with one or more conservation practices appears to decline with successively higher potential erosion (Committee on Conservation Needs and Opportunities, 1986).

Interest in conservation tillage can also be attributed to the lack of available labor, high fuel prices, potential increases in farm profit, more effective soil applied and post-emerge herbicides, inexpensive equipment modifications, increased farmer awareness, and improved educational programs. However, tradition is one of the largest deterrents to the adoption of conservation tillage. Even though soil erosion is a major problem, farmer concerns about possible yield decreases, inadequate weed control, fertilizer requirements, and soil responses to fewer tillage operations have delayed widespread implementation of conservation tillage. Such attitudes are not changed easily.

In response to the above-mentioned needs, the University of Nebraska Cooperative Extension developed area conservation tillage meetings to educate clients about the adoption and management of conservation tillage systems. The meetings were part of an overall educational program that included sprayer, planter, and cultivator clinics; equipment demonstrations; tours of farmer plots and fields; rainfall simulator demonstrations to show the erosion control potential of different levels of residue cover; development of educational materials; and a balanced media approach involving press releases, magazine articles, radio programs, and television coverage.

The overall goal of the area conservation tillage meetings was to educate farmers, landowners, and local agency personnel about how to successfully adopt and manage conservation tillage and planting systems. The purpose of this article is to report on the development, delivery, and successes of these meetings. 


\section{PROGRAM DEVELOPMENT}

Prior to conducting the first area conservation tillage meeting, conservation tillage in-service training programs were conducted for extension agents at four locations in Nebraska in November 1980. Written materials were developed to support these 1-d multidisciplinary training sessions.

In 1981, several counties incorporated conservation tillage subject matter into their crop and production meetings, but a program totally dedicated to conservation tillage was not conducted that year. However, extension agents and farmers continually requested information about adoption and use of conservation tillage. Therefore, a conservation tillage ad hoc committee comprising representatives from several disciplines, extension agents, and Soil Conservation Service (SCS) personnel, was formed to develop a comprehensive educational program. In contrast to several on-going educational programs at that time, this committee decided to deliver the conservation tillage educational program on an area or regional basis rather than on a county basis. Reasons for this decision included a large potential clientele demand, limited financial resources, and the need for efficient use of extension specialists' and agents' time.

The first area conservation tillage meeting was conducted in Lincoln on the University of Nebraska campus in March 1982, and was attended by approximately 150 . The 2 -d program included nearly every facet of conservation tillage as well as farmer presentations and was similar to that described by Riehle (1986). Because approximately two-thirds of the audience were personnel from various agencies, this meeting served primarily as an in-service training program for agency personnel but did not achieve the goal of educating a large number of farmers and landowners.

Since farmer attendance was low in 1982, the ad hoc committee decided to take the area conservation tillage meetings to the farmers in 1983. Six 1-d area meetings were conducted in eastern and south-central Nebraska in February. Total attendance at these meetings was 685 and the majority of the attendees were farmers. Farmer responses to the meetings were excellent and $50 \%$ of the respondents to an evaluation form indicated they would be changing their tillage practices because of information delivered at the meeting.

As a result of the 1982 and 1983 tillage meeting successes, the ad hoc committee decided to continue this educational approach. However, the number of agent requests to host a meeting exceeded the time available to conduct full-day programs. Thus, half-day formats were developed to accommodate more meeting sites. Currently, the most popular meeting format is a half-day program. Because of time limitations, only four or five topics addressing the most pressing clientele needs can be presented. The full-day format allows a broader spectrum of information to be presented and discussed and is more appropriate for first-time users of conservation tillage.
Additional inservice training programs for extension agents and SCS personnel have also been conducted. The ad hoc committee was replaced in 1989 by the Soil Erosion Team, which is part of the University of Nebraska Cooperative Extension Priority Initiative on Conserving and Managing Natural Resources. This team now provides overall direction for the conservation tillage program.

\section{RESPONSIBILITIES}

Success of the area conservation tillage meetings involves input from several individuals whose key responsibilities are outlined in the following sections.

\section{Coordinator}

The program coordinator for the area conservation tillage meetings serves on the multidisciplinary Soil Erosion Team and provides overall guidance to the educational program. With input from extension specialists, extension agents, and SCS representatives, the coordinator is responsible for soliciting subject matter to be presented; working with host agents to determine program content; ensuring that written materials are developed; coordinating with other program leaders to avoid time conflicts among specialists and meeting locations; and providing publicity at the state level.

The coordinator generally works with the Soil Erosion Team to develop ideas regarding program format, prioritize educational needs, and discuss potential meeting locations. Appropriate specialists are then contacted and given the opportunity to submit presentation titles that address the needs expressed or which report on new research or advances in conservation tillage. A list of topics and potential speakers is forwarded to host agents for consideration by their local planning committees. Following input from the planning committee, the coordinator and host agent select the desired topics and propose an agenda for a particular location. Coordination with speakers follows, and the agendas are finalized. Thus, each meeting is tailored to meet local conservation tillage needs.

A single proceedings that contains written information provided by the specialists regarding most proposed topics is compiled by the coordinator and published annually (e.g., Univ. of Nebraska Coop. Ext., 1990). Desktop publishing is used to prepare a high quality publication. An advance copy of the proceedings is forwarded to farm magazines for their use, and often results in magazine articles that further promote the meetings. A copy of the proceedings is given to each attendee and serves as a reference in that it contains information on aspects of conservation tillage that may not have been presented at a particular location.

\section{Host Extension Agent}

The host extension agent has many responsibilities to ensure that the area meeting will be successful. The most 
important task is to involve extension agents and SCS personnel from surrounding counties so that every person feels they are part of a team that has responsibility for the area meeting. These people, along with local agribusiness representatives and one or two farmers, form a planning committee for an individual meeting. Without this involvement, the area meeting simply becomes a county or local meeting with limited participation from other counties.

The host generally moderates the opening part of the program to help make the audience feel welcome. Introductions of other agents, SCS personnel, or the planning committee; objectives of the meeting; and a statement regarding what is to be taught is typical. These comments help set the tone of the meeting, which influences questions, discussion, and audience participation.

The host agent also has financial responsibilities for local activities. With input from the planning committee, costs of meals, refreshments, publicity, room rental fees, proceedings, and other items must be determined. Income from commercial exhibits or other contributors must be estimated. These estimates of expenses and income are used to determine a registration fee.

Extension agents are encouraged to actively participate in the presentations. As an example, some host agents have training in economics, and thus are well qualified and logical choices for leading an economic discussion of various tillage and planting alternatives. Specialists may assist agents in developing and preparing their presentations. By taking this more visible role, these agents enhance their credibility and reputation in the community.

\section{Local Planning Committee}

The planning committee reviews the list of potential presentation topics and may suggest additional topics that will better meet local needs and concerns. The planning committee may also choose to present part of the information. The host agent should delegate responsibilities such as local publicity, meeting facilities and refreshments, and selection of farmers to be on the program to other planning committee members, thereby reducing the agent's time commitment and further enhancing the feeling of cooperation among the planning committee.

Arranging for commercial exhibits is another responsibility of the local planning committee. These exhibits often include local equipment, chemical, and seed dealers; financial institutions; and federal, state, or local agencies. Commercial exhibitors are charged a fee, generally less than $\$ 50$, which is used to help defray meeting expenses. Exhibitors are introduced during the program and often given 2 or 3 min to highlight their products or programs. Outdoor equipment exhibits have been used, but February weather must be considered when planning such displays. Soliciting potential exhibitors from the local area is important. To assist with planning, a list of exhibitors who supported previous conservation tillage meetings is also maintained.
The planning committee is responsible for planning and conducting the local publicity campaign that generally involves newspaper releases, radio announcements, posters in local businesses, and mailing of brochures to potential attendees. Some planning committees purchased advertising space in the local newspaper in addition to using press releases and/or the extension agent's weekly newspaper column. Others have included their brochure with the Agricultural Stabilization and Conservation Service regular mailings to clientele.

The planning committee also has the responsibility of selecting farmers for speakers or as panel members. Farmers are a critical part of the program because they tend to have greater credibility with other farmers than do extension or agency speakers. Generally, these presentations include a description of the tillage and planting system being used, equipment attachments or modifications, weed control strategies, and solutions to problems that they may have encountered. The agent or another member of the planning committee may help guide a panel of three of four farmers through a series of questions.

Since the farmer presentations are very popular and informative, they are generally held toward the latter part of the meeting. As such, the audience tends to stay until the meeting is over rather than leaving during a break in the program. Farmer presentations have also been used immediately following a specialist's presentation to provide a real life description or solution to a particular subject.

\section{Extension Specialists}

Extension specialists are the primary speakers at area conservation tillage meetings. They have the responsibility of contacting the various host agents to determine specific needs to be addressed. Being aware of recent subject matter developments, adapting information from the literature, and developing a format for the presentation are also the responsibility of the specialists.

Specialists who prepare adequately rarely use the same presentation from one meeting location to another. Local conditions such as cropping patterns, soil types, and climate often cause recommendations to change from site to site. Farmers are both quick and correct to criticize information or data that cannot easily be adapted or transferred to their situation.

The specialist must also make a choice on how to present the information. Audience size often limits the use of a video tape unless specialized equipment is available locally. Careful management is required such that a slide-tape set does not bore the audience. Regardless of the method of presentation, high quality visuals are required. Slides or transparencies with too much or unreadable information have resulted in poor speaker evaluations. Because meeting participants become less attentive when presentations exceed 25 or $30 \mathrm{~min}$, specialists are encouraged to use no more than 20 to 25 min for a formal presentation. Generally 5 to $10 \mathrm{~min}$ are allowed for discussion immediately following each presentation. 
Table 1. Survey of attendees at area conservation tillage meetings planning to adopt conservation tillage practices by year.

Year

\begin{tabular}{lrrrrrrrr}
\cline { 2 - 8 } Survey information & 1983 & 1984 & 1985 & 1986 & 1987 & 1988 & 1989 & 1990 \\
\hline Number of meetings & 6 & 10 & 8 & 10 & $14 \dagger$ & $14 \ddagger$ & $17 \S$ & $16 \uparrow$ \\
$\begin{array}{l}\text { Attendees } \\
\begin{array}{l}\text { Attendees filling out } \\
\text { questionnaire }\end{array}\end{array}$ & 315 & 425 & 403 & 432 & 421 & 565 & 495 & 451 \\
$\begin{array}{l}\text { Plan to change } \\
\text { tillage practices } \\
(\%)\end{array}$ & 50 & 75 & 80 & 84 & 80 & 80 & 76 & 70 \\
\end{tabular}

$\dagger 1987$ includes four half-day meetings.

$\ddagger 1988$ includes seven half-day meetings.

\& 1989 includes 10 half-day meetings.

1990 includes 13 half-day meetings.

\section{MEETING EVALUATIONS}

Total meeting attendance peaked in 1988 at 1150 (Table 1). The average attendance (1983-1990) at full-day and half-day meetings was 84 and 56, respectively. Although half-day meetings were not as well attended, the resources needed to conduct a half-day program were considerably less than those required for a full-day program.

Evaluation forms distributed near the end of the meeting were used to assess program effectiveness at nearly every meeting since 1982 . A one-page questionnaire was designed to obtain information concerning attendees' occupation, current levels of residue cover, area farmed, and their perceptions of beneficial as well as negative aspects of the meeting. Generally, about $50 \%$ of the attendees responded to the questionnaire.

Evaluation forms also inquired about farmer plans to change tillage practices as a result of the information presented. Between 1985 and 1989, about $80 \%$ of the farmers who completed a questionnaire indicated they would be changing their tillage practices as a result of the information presented (Table 1). In 1983, only 50\% of the respondents indicated they would change their tillage practices. Because of improved progress and a growing interest in conservation tillage, the positive response to this question increased in 1984 and 1985 and remained relatively constant until 1989 . In 1990, the response was only $70 \%$. This decrease was caused in part by the 1985 Food Security Act, which required that approved conservation plans be developed by January 1990. Some 1990 attendees indicated that the conservation compliance plans were causing them to change, whereas other attendees indicated that they had already adopted no-till or another conservation tillage system.

Changes cited by farmers included elimination of a tillage operation and the adoption of no-till planting corn (Zea mays L.) into soybean [Glycine max (L.) Merr.] residue. Between 1984 and 1988, field surveys of producers in eastern Nebraska showed a reduction in residue-altering operations and a threefold increase in the use of no-till planting systems (Jasa et al., 1989). This information from the unrelated survey provides some evidence that farmers were following through on their plans to change tillage practices.

Meeting attendees were also asked about what should
Table 2. Area conservation tillage meeting attendees' preferences to get help in adopting conservation tillage.

\begin{tabular}{lcc}
\hline & \multicolumn{2}{c}{$\begin{array}{c}\text { Importance } \\
\text { value }\end{array}$} \\
\cline { 2 - 3 } Educational method & 1989 & 1990 \\
\hline Equipment demonstrations & 1.8 & 1.9 \\
In-depth meetings & 1.9 & 2.0 \\
Field tours & 2.1 & 2.0 \\
Factsheets & 2.5 & 2.4 \\
Farm magazine articles & 2.5 & 2.6 \\
Videos & 2.8 & 2.7 \\
Newspapers, agent's column, news articles & 3.0 & 2.9 \\
Small group meetings & 3.0 & 2.9 \\
Television & 3.3 & 3.5 \\
Radio & 3.4 & 3.6 \\
\hline
\end{tabular}

$\dagger 1=$ Most important, $5=$ not important.

be added or expanded for future meetings. Responses to this question usually included more equipment, specific weed control strategies, fertility recommendations and preferred methods of application, residue management, and more farmer presentations. These responses were used to form the working outline of the half-day programs. More than $95 \%$ of the 1989 and 1990 attendees indicated they would attend a similar meeting next year.

Since surveys showed that meeting participants would prefer to travel less than $40 \mathrm{~km}$ to attend a meeting, meeting locations were changed from year to year to provide access to different audiences. Further, tillage and planting practices are often localized, and changing locations provides more opportunity to address specific local concerns. A disadvantage is that a new set of host agents needs some training or refreshing each year regarding their responsibilities in planning and conducting the program.

Although the area conservation tillage meetings have been conducted since 1982 , about $40 \%$ of the 1989 and 1990 meeting participants had not attended a similar program before. This large percentage of new attendees was attributed to the fact that meeting locations are changed from year to year and to the conservation compliance requirements of the 1985 Food Security Act. However, because $60 \%$ of participants had previously attended a similar program, the need for additional area tillage meetings must be evaluated. As a partial response to this concern and to the evaluation form feedback regarding the need for more information on equipment and specific recommendations, in-depth planter clinics and small group meetings have been conducted to supplement the conservation tillage meetings. In 1990, 13 planter clinics were conducted; more clinics are planned for the future.

Attendees were asked to indicate how they learned about the meeting. In $1990,45 \%$ of the attendees learned about the meeting from a brochure and another $20 \%$ learned of the meeting from the extension agent. Because the extension agent generally mailed the meeting brochure, about $65 \%$ learned of the meeting through the agent. Another $18 \%$ learned of the meeting through a radio announcement or a newspaper release.

Attendees indicated the most desirable methods of learning more about conservation tillage include equipment demonstrations, in-depth meetings, and field 
Table 3. Average meeting expenses per attendee in 1989.

\begin{tabular}{lrr}
\hline Expenses & Full-day & Half-day \\
\hline Meals, refreshments & $\$ 4.97$ & $\$ 0.41$ \\
Proceedings & 3.50 & 3.50 \\
Brochures & 1.52 & 0.95 \\
Postage $\dagger$ & 0.51 & 0.89 \\
Meeting room rent & 0.53 & 0.28 \\
Total & $\$ 11.03$ & $\$ 6.03$ \\
\hline
\end{tabular}

$\dagger$ Incomplete or missing information

tours (Table 2). Radio and television programs were least desirable.

\section{MEETING EXPENSES}

In 1989, the average meeting expense per attendee at full-day and half-day meetings was approximately $\$ 11$ and \$6, respectively (Table 3 ). The major difference was attributed to the meal included with the full-day meetings. These meeting expenses are recovered primarily through a combination of registration fees, exhibitor fees, and contributions from supporting agencies or organizations. Travel expenses for specialists were paid by appropriate departmental operating budgets. Registration fees have generally been under $\$ 10$, and more than $99 \%$ of the attendees indicated that the meeting registration fee have been fair.

\section{CONCLUSIONS}

The area conservation tillage meetings have proven to be a successful part of a comprehensive educational program having the objective of helping farmers and landowners adopt and manage conservation tillage systems. As with many educational programs, the full impact will not be known for a number of years because farmers slowly change tillage practices, trying new technologies on an experimental basis before implementing the practices on entire farms. Meeting evaluations have shown that $80 \%$ of the attendees planned on making a change in their tillage systems as a result of the information presented at the meeting.

The multidisciplinary program has included farmer presentations and incorporates planning at the local level to ensure that local needs are addressed. By supplementing the area meetings with field days, equipment demonstrations, and other educational methods, many Nebraska farmers have learned how to adopt and manage conservation tillage systems.

\section{REFERENCES}

Committee on Conservation Needs and Opportunities. 1986. Assessing conservation practices and land classification schemes. Soil conservation-assessing the national resources inventory. Vol 1. Board on Agriculture. National Research Council, National Academy Press, Washington, DC.

Conservation Technology Information Center. 1989. 1989 National survey of conservation tillage practices. CTIC, West Lafayette, IN.

Jasa, P.J., E.C. Dickey, and S.R. Smydra. 1989. Conservation tillage component of the Agricultural Energy Conservation Project Final Rep. Univ. of Nebraska Coop. Ext., Lincoln, NE.

Nebraska Natural Resources Commission. 1979. Section 208 Water Quality Management Plan for the State of Nebraska. NNRC, Lincoln, NE.

Nowak, P.J. 1985. Obstacles to adoption of conservation tillage. J. Soil Water Conserv. 38(3):162-165.

Riehle, H. 1986. How to organize a successful conservation tillage conference. J. Soil Water Conserv. 41(1):28-29.

University of Nebraska Cooperative Extension. 1990. Conservation tillage. Proc. no. 9. Univ. of Nebraska Coop. Ext., Lincoln, NE. 